\title{
Segunda Parte - As vilas e seus territórios: dependências, rivalidades e hierarquias
}

\author{
Cláudia Damasceno Fonseca
}

\section{SciELO Books / SciELO Livros / SciELO Libros}

FONSECA, C.D. As vilas e seus territórios: dependências, rivalidades e hierarquias. In: Arraiais e vilas d'el rei: espaço e poder nas Minas setecentistas [online]. Belo Horizonte: Editora UFMG, 2011. Humanitas series, pp. 265-269. ISBN: 978-85-423-0307-0.

https://doi.org/10.7476/9788542303070.0009.

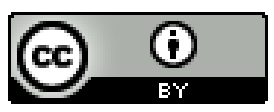

All the contents of this work, except where otherwise noted, is licensed under a Creative Commons Attribution 4.0 International license.

Todo o conteúdo deste trabalho, exceto quando houver ressalva, é publicado sob a licença Creative Commons Atribição 4.0.

Todo el contenido de esta obra, excepto donde se indique lo contrario, está bajo licencia de la licencia Creative Commons Reconocimento 4.0. 
Segunda Parte

AS VILAS E SEUS TERRITÓRIOS
DEPENDÊNCIAS, RIVALIDADES E HIERARQUUAS 
“(...) pelos muitos e relevantes serviços que tem feito [a Câmara de Vila Nova da Rainha] depois do seu estabelecimento, há perto de vinte anos (...).

Que o dito Senhor lhe conceda os privilégios da Câmara da Cidade do Porto, graça que tem concedido a várias vilas que nao desmerecem aquela, e sim por ser a mais populosa que se acha nas Minas, como pelo tratamento das pessoas que a povoam, sendo todos brancos, e de distinção, por cujo respeito os Governadores que têm ido às Minas, assim para os negócios particulares do Real Serviço, como para todas as juntas que se fazem sobre o governo delas e a melhor direção para a arrecadação da Real Fazenda, os mandam chamar, indo prontamente sem embargo da distância e despesa, sem mais interesse que o zelo do Real Serviço de Sua Majestade."

(Representação da Câmara da Vila Nova da Rainha do Caeté, 6 de junho de 1727, AHU, cx. 10, doc. 63.)

Nos capítulos precedentes, analisamos as criações de circunscrições eclesiásticas e civis ao longo de todo o período colonial, relacionando-as com as diretivas metropolitanas, mas também com o processo de povoamento e de constituição dos limites da capitania. Tentaremos agora demonstrar que estes centros do poder civil e religioso não eram núcleos inertes, ou entidades passivas. As "cabeças" das circunscrições mantinham entre si vários tipos de relações, e cada uma delas também interagia com os arraiais e com as zonas rurais circunvizinhas, que lhes estavam subordinadas. Estas relações, muitas vezes marcadas pela emulação e pelo conflito, condicionavam a criação de novas circunscrições. 
A partir da metade do século XVIII, diversas câmaras de Minas Gerais envolvem-se em disputas territoriais, as quais ocorrem paralelamente aos conflitos de jurisdição entre os governadores, abordados anteriormente. Aliás, trata-se, muitas vezes, de um mesmo combate: as fronteiras da capitania, disputadas pelos capitães-generais, coincidiam com os limites dos termos de vilas como São João del-Rei e São Bento do Tamanduá, o que explica a participação ativa na defesa do território mineiro por parte destas câmaras, que se opuseram - conforme vimos - às autoridades de São Paulo e de Goiás.

Porém, a maior parte dos conflitos diz respeito à formação dos limites internos da capitania: não somente dos concelhos, mas também de paróquias e comarcas. Em alguns casos, as câmaras mineiras disputaram a posse dos núcleos de povoamento que surgiam nos confins imprecisos de seus territórios de jurisdição (termos). Em outras situações, não se tratava de querelas entre municipalidades, mas de conflitos de interesses entre um arraial desejoso de autonomia (ou seja, de uma povoação que pretendia ser elevada à condição de vila, sede de um novo concelho) e a vila à qual este arraial estava subordinado, que se opunha ao desmembramento de seu território. Em ambos os casos, as câmaras eram guiadas por uma necessidade considerada "vital": estender e consolidar os limites dos seus termos.

A fim de revelar outros aspectos e outros atores do processo de formação das circunscrições, analisaremos, nos capítulos seguintes, documentos tais como requerimentos enviados a Lisboa pelos arraiais (pedindo sua emancipação ou sua anexação a uma determinada vila), representações das câmaras versando sobre disputas territoriais, assim como pareceres emitidos pelas autoridades da capitania. Levando-se em conta tais dados, poderemos completar a análise apresentada anteriormente, que focalizou as relações entre a fundação das vilas e o contexto econômico e político global da capitania na segunda metade do século XVIII. Com efeito, a criação de novas vilas nesse período parece ter contribuído para a resolução de alguns conflitos territoriais entre Minas e as capitanias limítrofes.

Nestas cartas e requerimentos, encontramos representações variadas das vilas e de seus termos. Um grande número de discursos diz respeito à dimensão territorial das vilas: no momento 
da (re)definição dos limites dos concelhos, vários tipos de argumentos são mobilizados para justificar a inclusão de arraiais em determinada circunscrição, ou para comprovar a necessidade da criação de um novo centro de poder local. Outros discursos presentes nesta documentação revelam o papel e o valor simbólico atribuídos às sedes de circunscrições e à aparelhagem administrativa e judiciária, bem como os critérios que os contemporâneos consideravam pertinentes para avaliar a capacidade de uma aglomeração em se autogerir. Justificativas de ordens diversas - geográfica, demográfica, econômica, sociocultural foram utilizadas por diferentes atores, a fim de provar a vocação ou, ao contrário, a inaptidão dos arraiais a ostentar certos títulos (vila, cidade) e a exercer certas funções administrativas (sede de julgado, de concelho ou de comarca).

Estes conflitos e os discursos por eles suscitados permitem entrever a complexidade das relações entre as vilas e os arraiais, o que demonstra que estamos em presença de uma verdadeira rede urbana - pouco importando a definição que se atribua a esse conceito polissêmico e ambíguo. ${ }^{1}$ De fato, as fontes históricas comprovam a existência de relações entre as vilas e as zonas rurais circundantes (relações ligadas à questão do abastecimento), de fluxos interurbanos (relações entre as unidades urbanas e a rede viária), assim como a presença de zonas de influência (administrativa, religiosa, comercial) das diversas vilas e arraiais de Minas Gerais sobre as terras circunvizinhas.

No entanto, é importante notar que as fontes disponíveis não permitem uma análise detalhada de cada um desses aspectos das relações interurbanas - os quais, frequentemente, aparecem como simples alusões nos discursos contemporâneos. Nosso interesse será focalizado nos argumentos que justificam as situações de subordinação das povoações a determinadas vilas e que revelam os critérios então utilizados para avaliar os espaços e os territórios urbanos.

Insistimos, porém, na ideia de rede, pois este conjunto de aglomerações não pode ser visto apenas como "a soma das unidades que o compõem" - ou seja, como um simples conjunto de pontos distribuídos sobre um território, configurando uma "semeadura" (semis) ou uma "constelação" de lugares indiferenciados -, tampouco como uma "armadura urbana" (armature urbaine), o que 
suporia considerar somente as relações hierarquizadas - ou seja, aquelas diretamente ligadas à administração. ${ }^{3}$

Contudo, se parece evidente que os estabelecimentos mineiros funcionavam em rede, o conceito de "urbanidade" merece ser aprofundado: poder-se-ia qualificar de "urbana" cada uma das aglomerações que compõem a rede em questão? Para além da hierarquia imposta pela administração civil e eclesiástica, trata-se de determinar outros indicadores dos diferentes níveis de urbanização das vilas e arraiais da capitania - o que implica uma leitura crítica das fontes disponíveis e úteis ao estabelecimento de uma "escala graduada" da urbanidade em Minas Gerais. 


\section{EDITORAufmg}

\section{As notas a seguir correspondem a Primeira Parte, originalmente reunidas ao final desse livro.}

pp. 629

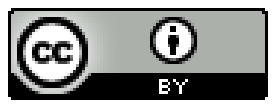

All the contents of this work, except where otherwise noted, is licensed under a Creative Commons Attribution 4.0 International license.

Todo o conteúdo deste trabalho, exceto quando houver ressalva, é publicado sob a licença Creative Commons Atribição 4.0.

Todo el contenido de esta obra, excepto donde se indique lo contrario, está bajo licencia de la licencia Creative Commons Reconocimento 4.0. 


\section{SEgunda Parte \\ AS VILAS E SEUS TERRITÓRIOS DEPENDÊNCIAS, RIVALIDADES E HIERARQUIAS}

1 Sobre a variedade de noções e abordagens geográficas ligadas às expressões "rede urbana", "armadura (armature) urbana, "sistema de cidades" etc., ver: PUMAIN; ROBIC. Réseaux urbains, p. 72-75; cf., ainda: PUMAIN; ROBIC. Théoriser la ville, p. 107-162.

2 LEPETIT Les villes dans la France moderne (1740-1840), p. 173

3 Ver os artigos semis e armature urbaine em: BRUNET; FERRAS; TIÉRY. Les mots de la géographie.

\section{Capinuto 5}

\section{CONHUTOS THRRTORIAIS E A GÊNESE DOS} HMITES MUNICIPAIS

1 Esta coincidéncia de limites so se verificou até 17ı, quando a vila de São José foi criada.

2 Carta de Dom Lourenco de Almeida ao rei de Portugal, 18 de junho de 1731, apud CARVALHO. Creacào de comarcas nos tempos coloniaes, p. 424.

3. TKINDADE. Instituigies de ignjias no bispado de Mariana, p. 232.

* Hespavila. As ribpris do Leriatham, p. 55.

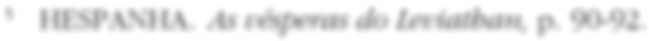

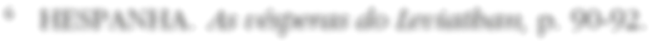

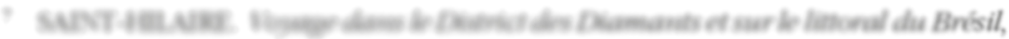
L. L. p. $2 m$

" Conedla do Consellwo Uhramarino", datada de 23 de agosto de 1730 , citada

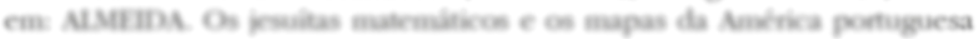
(1730.1745), p. 82

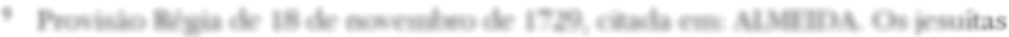

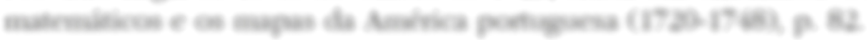

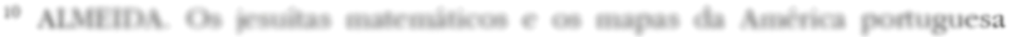
(1720-1748), p. 84.

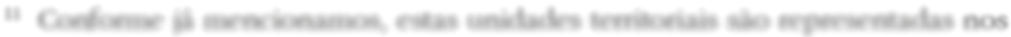

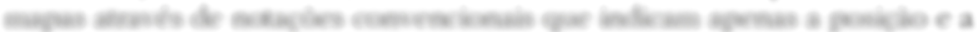

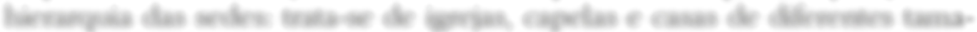

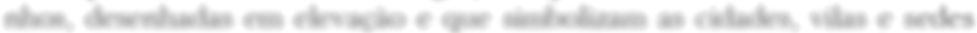

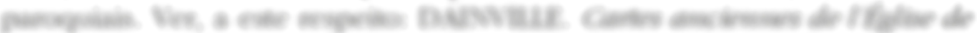

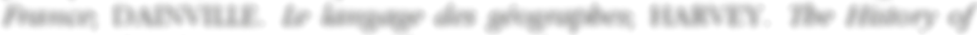
Topesnapbical Maps IVNAM. Me Mapmabris. At.

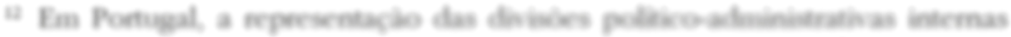

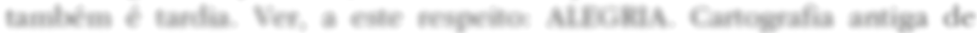
Portugal continmeal, p. $169-210$, ALEKLA; GARCA. Evolugào da cartografia portuguesa, p. $50-84$. 